\title{
Characterizing overwater roughness Reynolds number during hurricanes
}

\author{
S. A. $\mathrm{Hsu}^{1,2}$ (D) Hui Shen ${ }^{1,3} \cdot{\text { Yijun } \mathrm{He}^{1}}^{1}$
}

Received: 18 May 2017 / Accepted: 17 November 2017 / Published online: 24 November 2017

(c) The Author(s) 2017. This article is an open access publication

\begin{abstract}
The Reynolds number, which is the dimensionless ratio of the inertial force to the viscous force, is of great importance in the theory of hydrodynamic stability and the origin of turbulence. To investigate aerodynamically rough flow over a wind sea, pertinent measurements of wind and wave parameters from three data buoys during Hurricanes Kate, Lili, Ivan, Katrina, Rita, and Wilma are analyzed. It is demonstrated that wind seas prevail when the wind speed at $10 \mathrm{~m}$ and the wave steepness exceed $9 \mathrm{~m} \mathrm{~s}^{-1}$ and 0.020 , respectively. It is found that using a power law the roughness Reynolds number is statistically significantly related to the significant wave height instead of the wind speed as used in the literature. The reason for this characterization is to avoid any self-correlation between Reynolds number and the wind speed. It is found that although most values of $R_{*}$ were below 500, they could reach to approximately 1000 near the radius of maximum wind. It is shown that, when the significant wave height exceeds approximately $2 \mathrm{~m}$ in a wind sea, the air flow over that wind sea is already under the fully rough condition. Further analysis of simultaneous measurements of wind and wave parameters using the logarithmic law indicates that the estimated overwater friction velocity is consistent with other methods including the direct (eddy-covariance flux) measurements, the atmospheric vorticity approach, and the sea-surface current measurements during four slow moving super typhoons with wind speed up to $70 \mathrm{~m} \mathrm{~s}^{-1}$.
\end{abstract}

\section{Introduction}

Reynolds number is a key parameter in the theory of hydrodynamic stability and the origin of turbulence, which is of great importance to understand dynamical mechanisms of air-sea interactions. For a history of the Reynolds number, see Rott (1990). This number has been used in atmosphere-ocean interaction (see, e.g. Kraus and Businger 1994) and air-sea interaction (see, e.g. Csanady 2001). For its usage in hurricane physics, see, e.g. Anthes (1982), Davis

Responsible Editor: S.-T. Castelli.

S. A. Hsu

sahsu@1su.edu

1 School of Marine Sciences, Nanjing University of Information Science and Technology, Nanjing 210044, China

2 Coastal Studies Institute and Department of Oceanography and Coastal Sciences, Louisiana State University, Baton Rouge, LA 70803, USA

3 Bedford Institute of Oceanography, Fisheries and Oceans, Dartmouth B2Y 4A2, Canada et al. (2008), Kantha (2008), Smith and Montgomery (2010), Zeng et al. (2010), and Liu et al. (2011). An extensive literature survey related to the wind-stress parametrization at air-sea interface has been conducted by Bryant and Akbar (2016).

According to Andreas et al. (2012), for aerodynamically rough flow over the ocean:

$U_{10} \geq 9 \mathrm{~m} \mathrm{~s}^{-1}$,

$R_{*}=U_{*} Z_{0} / \nu \geq 2.5$ for fully rough flow, and

$U_{*}=0.0583 U_{10}-0.243$.

Here $U_{10}$ is the wind speed at $10 \mathrm{~m} R_{*}$ is the roughness Reynolds number, $U_{*}$ is the friction velocity, $Z_{0}$ is the roughness length and $v\left(=1.46 \times 10^{-5} \mathrm{~m}^{2} \mathrm{~s}^{-1}\right)$ is the kinematic viscosity of air.

Because there are large scatters in the relation between $R_{*}$ and $U_{10}$ (Andreas et al. 2012, Figs. 3, 4), an independent parameterization for the roughness Reynolds number is needed. Since there were no estimations of $R_{*}$ using independent parameter such as the significant wave height, $H_{\mathrm{s}}$, based on buoy measurements during a hurricane available in the literature, it is the purpose of this study to find such 
relation between $R_{*}$ and $H_{\mathrm{s}}$ under the fully rough flow over the wind seas during hurricanes.

\section{Datasets and criteria used in this study}

\subsection{Datasets for this study}

Simultaneous measurements of wind $\left(U_{10}\right)$ and significant wave height $\left(H_{\mathrm{s}}\right)$ and peak or dominant wave period $\left(T_{\mathrm{p}}\right)$ from three data buoys during six hurricanes are analyzed. These datasets are listed in Table 1.

\subsection{Criterion for atmospheric stability}

To investigate the roughness over the water surface, atmospheric stability conditions need to be determined first. According to Hasse and Weber (1985), overwater stability categories may be estimated using a graphic approach from the measurements of wind speed and air and sea temperature difference. An example is provided in Fig. 1 for Hurricane Kate (see also Hsu 2003). On the basis of Fig. 1, stability "D" prevailed during the entire period (see Table 1), indicating that the stability is near-neutral so

Table 1 Data sources used in this study based on buoy measurements by the National Data Buoy Center (NDBC) (see http://www.ndbc. noaa.gov) during wind seas when $U_{10} \geq 9 \mathrm{~m} \mathrm{~s}^{-1}$ and $H_{\mathrm{s}} / L_{\mathrm{p}} \geq 0.020$

\begin{tabular}{lccccc}
\hline Hurricane & Year & Month & Date & Buoy & $U_{10}, \mathrm{~m} \mathrm{~s}^{-1}$ \\
\hline Kate & 1985 & 11 & $19-21$ & 42003 & $9-47$ \\
Lili & 2002 & 10 & $1-3$ & 42001 & $9-47$ \\
Ivan & 2004 & 9 & $12-16$ & 42003 & $9-28$ \\
Katrina & 2005 & 8 & $26-28$ & 42003 & $9-29$ \\
Rita & 2005 & 9 & $21-24$ & 42001 & $10-41$ \\
Wilma & 2005 & 10 & $19-24$ & 42056 & $12-32$ \\
\hline
\end{tabular}

that the logarithmic wind profile law is valid (see, e.g., Hsu 2003; Vickery et al. 2009). Similar neutral stability conditions prevailed during other five hurricanes as listed in Table 1.

\subsection{Criteria for wind speed and wind seas}

To minimize the effects of swell, conditions under the wind sea are investigated next. According to Drennan et al. (2005), a wind sea is defined when:

$H_{\mathrm{s}} / L_{\mathrm{p}} \geq 0.020$,

$L_{\mathrm{p}}=(g / 2 \pi) T_{\mathrm{p}}^{2}=1.56 T_{\mathrm{p}}^{2}$.

Here $H_{\mathrm{s}}$ is the significant wave height in meters, $L_{\mathrm{p}}$ is the dominant wave length in meters, $T_{\mathrm{p}}$ is the peak or dominant wave period in seconds, and $g$ is the gravitational acceleration $\left(=9.8 \mathrm{~m} \mathrm{~s}^{-2}\right)$. Note that the dimensionless parameter $H_{\mathrm{s}} / L_{\mathrm{p}}$ is called wave steepness, which was proposed by Hsu (1974) and later validated by Taylor and Yelland (2001) for use in the aerodynamic roughness parameterization across the air-sea interface. Using Eq. (4), all datasets during the period as stated in Table 1 are valid under the wind sea conditions.

In order to substantiate Eqs. (1) and (4), Figs. 2 and 3 are presented. The datasets are based on Hurricane Ivan (2004) measured at NDBC Buoy 42003, which was located on the right side of Ivan's track. Figure 2 shows that during the period as indicated, the meteorological-oceanographic (metocean) measurements illustrate that the atmospheric stability was near neutral. Figure 3 depicts that the wave steepness increased with the wind speed. When the wind speed was less than $9 \mathrm{~m} \mathrm{~s}^{-1}$, mixed seas were the general rule. On the other hand, when the wind speed exceeded approximately $9 \mathrm{~m} \mathrm{~s}^{-1}$, wind seas prevailed, in support of Eqs. (1) and (4).
Fig. 1 Time series 1 in the graph legend is for $U_{10}, 2$ for sea and 3 for air temperatures, respectively, as measured at NDBC Buoy 42003 during Hurricane Kate (data source: Table 1)

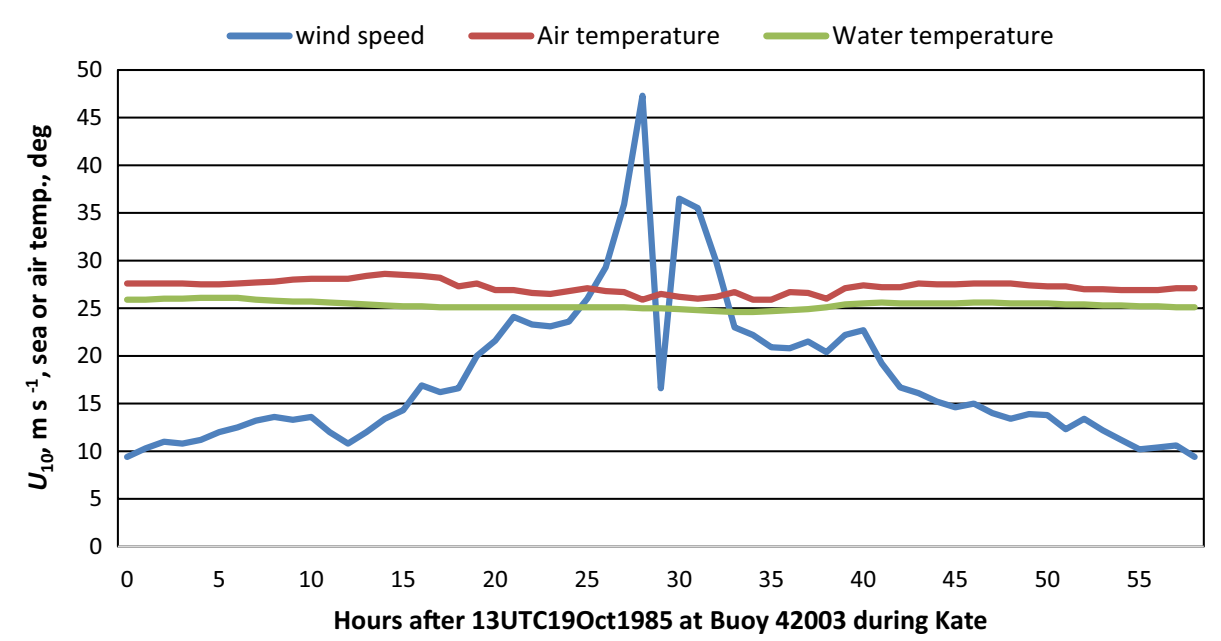




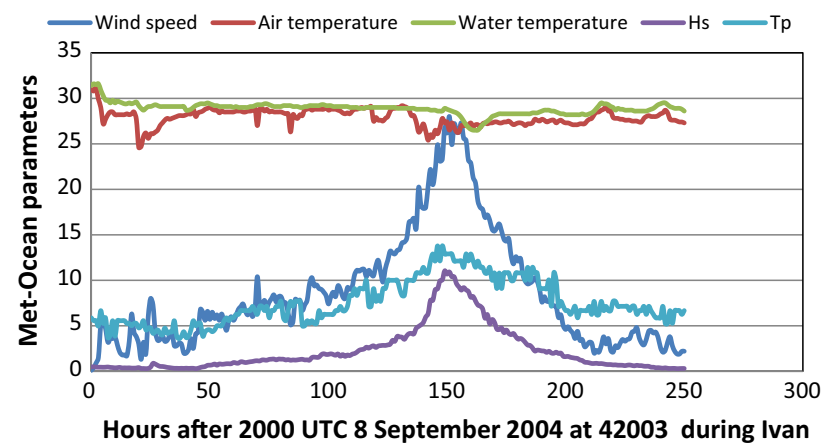

Fig. 2 Time series for Hurricane Ivan near Buoy 42003. In the graph legend, series 1 is for $U_{10}$ in $\mathrm{m} \mathrm{s}^{-1}$, series 2 and 3 are for air and sea temperatures in ${ }^{\circ} \mathrm{C}$, respectively, series 4 for $H_{\mathrm{s}}$ in m, and series 5 for $T_{\mathrm{p}}$ in seconds

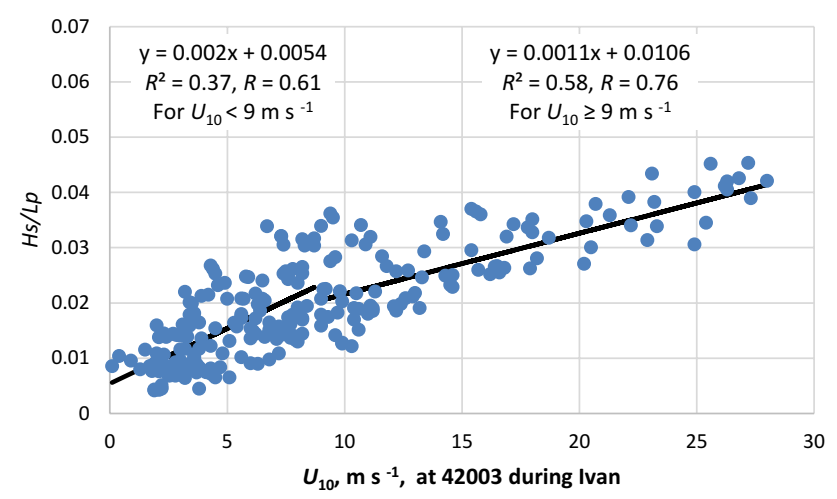

Fig. 3 Relation between wave steepness and wind speed for hurricane Ivan 2004. Black lines are linear regression for $U_{10}<9 \mathrm{~m} \mathrm{~s}^{-1}$ and $U_{10} \geq 9 \mathrm{~m} \mathrm{~s}^{-1}$, respectively

\section{Estimating overwater friction velocity}

The friction velocity, $U_{*}$, is a fundamental parameter in air-sea interaction (see, e.g., Csanady, 2001). In addition to Eq. (3), Edson et al. (2013) indicate that:

$U_{*}=0.062 U_{10}-0.28$.

Since Eqs. (3) and (6) are valid for $U_{10}$ up to $25 \mathrm{~m} \mathrm{~s}^{-1}$, it is the purpose of this section to test and extend these linear relations between $U_{*}$ and $U_{10}$ to much higher wind speed ranges using other methods.

\subsection{Using logarithmic wind profile law}

In the atmospheric boundary layer, under near-neutral stability conditions, the logarithmic wind profile is valid, particularly during a hurricane as demonstrated by Hsu (2003), that

$U_{10}=\left(U_{*} / k\right) \operatorname{Ln}\left(10 / Z_{0}\right)$,
Here $k(=0.4)$ is the von Karman constant, and $Z_{0}$ is the aerodynamic roughness length.

According to Taylor and Yelland (2001), for deep water,

$Z_{0} / H_{\mathrm{s}}=1200\left(H_{\mathrm{s}} / L_{\mathrm{p}}\right)^{4.5}$.

Using aforementioned formulas, our results are presented in Fig. 4, which shows that

$U_{*}=0.062 U_{10}-0.29$.

Figure 4 indicates that the coefficient of determination $R^{2}=0.95$, meaning that $95 \%$ of the variation between $U_{*}$ and $U_{10}$ can be explained by Eq. (9). In other words, if one accepts the high correlation coefficient $R=0.97$, Eq. (9) is useful in air-sea interaction. It is very surprising that Eq. (9) is almost identical to Eq. (6), indicating that the results obtained from the use of logarithmic wind-profile approach is as effective as the direct method using the eddycovariance flux measurements as employed by Andreas et al. (2012) and Edson et al. (2013).

\subsection{Using atmospheric vorticity method}

Equation (9) is further substantiated in Fig. 5. According to Anthes (1982, p. 71), $U_{*}$ can be estimated by the atmospheric vorticity method during a hurricane:

$U_{*}^{2}=U_{10} \zeta_{\mathrm{a}} h$,

where $\zeta_{\mathrm{a}}$ is absolute vorticity, $h$ is the height of hurricane boundary layer.

Based on the datasets of $U_{10}$ (used here as a surrogate) and $U_{*}$ as provided, Fig. 7 shows the results. Since the slope is unity and the correlation coefficient is 0.95 , one may say that Eq. (9) is further verified.

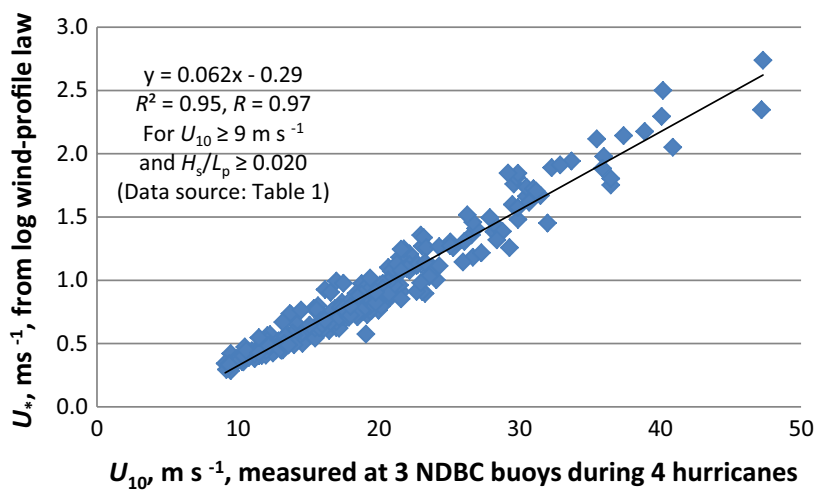

Fig. 4 Relation between $U_{*}$ and $U_{10}$ based on logarithmic windprofile law at three buoys during Kate. Lili, Rita, and Wilma (data source: Table 1) 


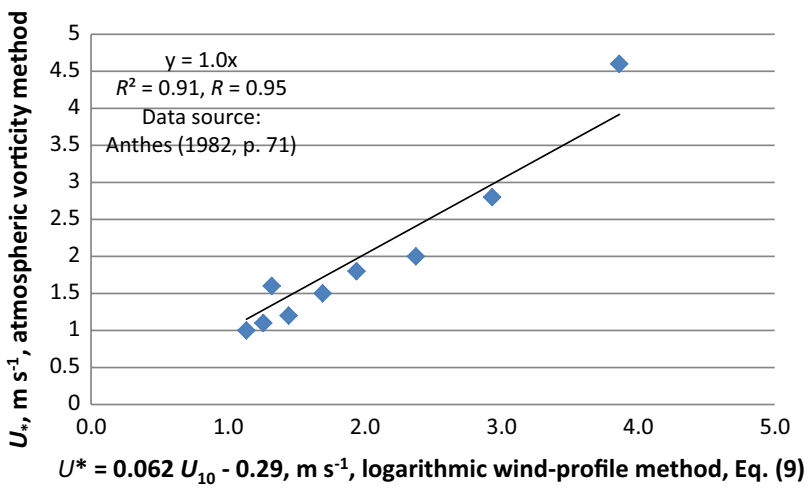

Fig. 5 Independent verification of Eq. (9) against the atmospheric vorticity method

\subsection{Using sea-surface current method}

According to Wu (1975),

$U_{\text {sea }}=0.55 U_{*}$.

Here $U_{\text {sea }}$ is the sea-surface drift velocity.

On the basis of observed near-surface currents during four super typhoons using drifters, Chang et al. (2014) provide the data for $U_{\text {sea }}$ under the conditions of three moving speeds of typhoons. To ascertain that those currents were induced by the wind, datasets from slow-moving typhoons are employed. Our results are presented in Fig. 6. Again, if one accepts the statistics shown in the figure, Eq. (9) is verified.

On the basis of aforementioned analysis and discussions, it is demonstrated that, when the wind speed exceeds $9 \mathrm{~m} \mathrm{~s}^{-1}$ during wind seas, the linear relation between overwater friction velocity and the wind sped at $10 \mathrm{~m}$ indeed exists as shown in Eq. (9). This formula is almost identical to that using the direct eddy-covariance flux measurements as provided in Eq. (6). Equation (9) is further verified independently using the

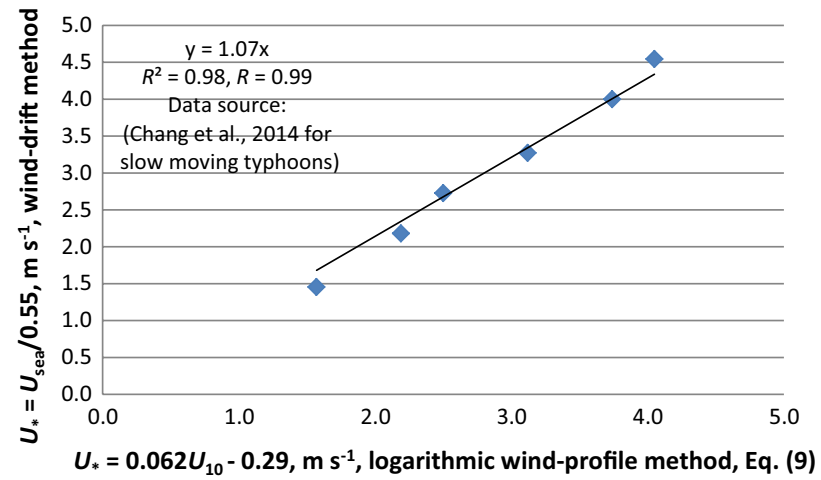

Fig. 6 Independent verification of Eq. (9) against the surface current method for slow-moving typhoons atmospheric vorticity method during a hurricane and using the sea-surface current velocity measurements by drifters during four super typhoons. Since Eqs. (6) and (9) are nearly identical and Eq. (6) is based on direct eddy-covariance method, Eq. (6) can now be extended up to the wind speed of $70 \mathrm{~m} \mathrm{~s}^{-1}$ and used in the following analysis.

\section{Estimating the roughness length}

As stated above, in the atmospheric boundary layer, under near-neutral stability conditions, the logarithmic wind profile is valid, particularly during a hurricane as demonstrated by Hsu (2003) and Vickery et al. (2009) that, from Eq. (7), we have:

$Z_{0}=10 \operatorname{Exp}\left(-0.4 U_{10} / U_{*}\right)$.

Now, using the measured $U_{10}, U_{*}$ and $Z_{0}$ can be computed from Eqs. (6) and (12), respectively.

\section{Characterizing the roughness Reynolds number}

On the basis of aforementioned analyses, we can now continue our search for the relation between $R_{*}$ and $H_{\mathrm{s}}$ as follows.

\subsection{Relation between $\boldsymbol{R}_{*}$ and $\boldsymbol{H}_{\mathrm{s}}$ during Kate}

From Eqs. (2), (6) and (12), $R_{*}$ can be computed. Figure 7 shows the relation between $R_{*}$ and $H_{\mathrm{s}}$ for Kate. If the coefficient of determination, $R^{2}=0.86$, meaning that $86 \%$ of the variation can be explained by the significant wave height or the high correlation coefficient, $R=0.93$, are acceptable, we have:

$R_{*}=0.78 H_{\mathrm{s}}^{3.0}$,

For $9 \leq U_{10} \leq 47 \mathrm{~m} \mathrm{~s}^{-1}$,

Equation (13) indicates that when $H_{\mathrm{s}} \geq 1.5 \mathrm{~m}$ in a wind sea, $R_{*} \geq 2$.6. According to Eq. (2) the air flow over this wind sea

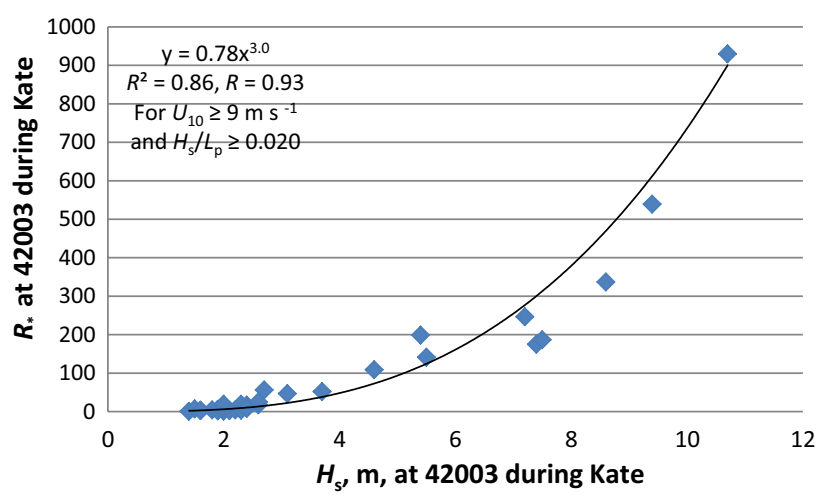

Fig. 7 Relation between $R_{*}$ and $H_{\mathrm{s}}$ at 42003 during Kate 
is fully rough, implying that the viscous effect on the wind sea is negligible and that the familiar logarithmic wind profile law is valid over the wind sea.

\subsection{Relation between $\boldsymbol{R}_{*}$ and $\boldsymbol{H}_{\mathrm{s}}$ during other five hurricanes}

Relations between $R_{*}$ and $H_{\mathrm{s}}$ during other five hurricanes are presented in Fig. 8a-e, respectively, that

For Lili, $\quad R_{*}=0.90 H_{\mathrm{s}}^{2.8}, \quad R^{2}=0.92, \quad R=0.96, \quad(14)$

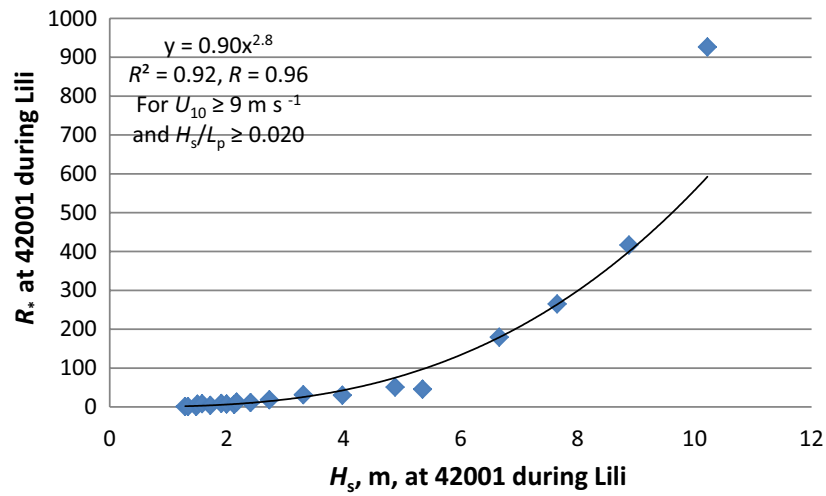

(a)

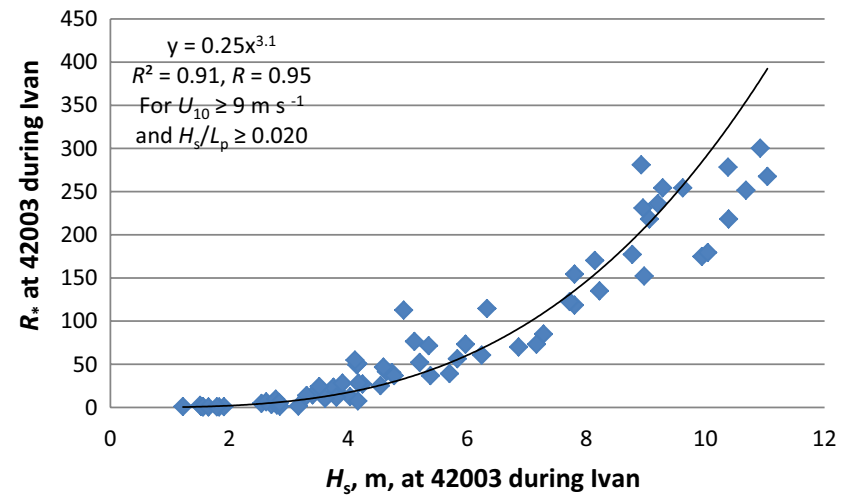

(b)
For Ivan, $\quad R_{*}=0.25 H_{\mathrm{s}}^{3.1}, \quad R^{2}=0.91, \quad R=0.95$,

For Katrina $, \quad R_{*}=1.28 H_{\mathrm{s}}^{2.2}, \quad R^{2}=0.89, \quad R=0.94$,

For Rita $, \quad R_{*}=0.67 H_{\mathrm{s}}^{2.3}, \quad R^{2}=0.85, \quad R=0.92$, and

For Wilma $, \quad R_{*}=0.29 H_{\mathrm{s}}^{3.1}, \quad R^{2}=0.92, \quad R=0.96$.

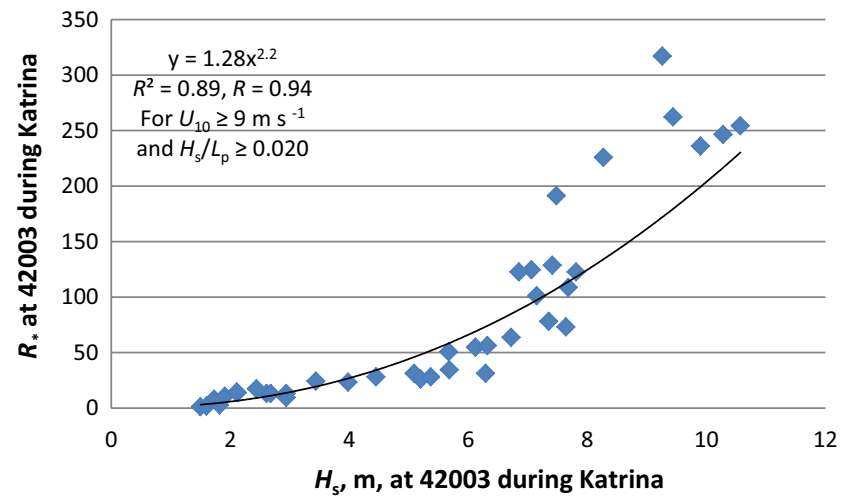

(c)

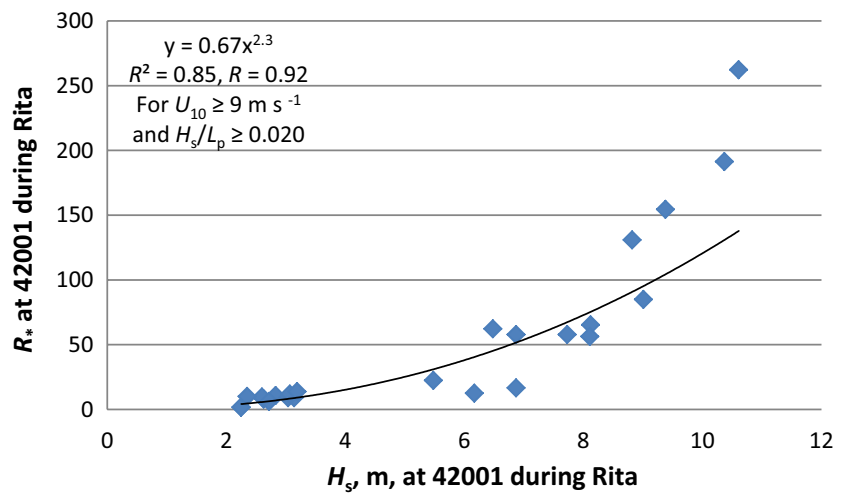

(d)

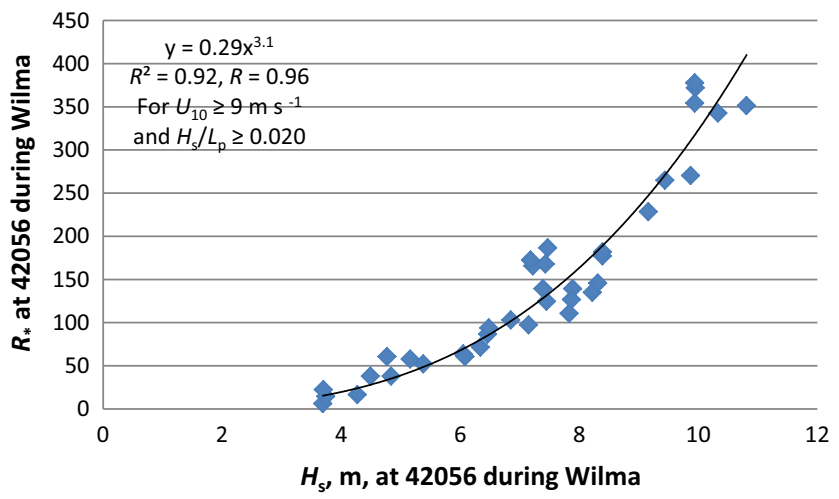

(e)

Fig. 8 Relation between $R_{*}$ and $H_{\mathrm{s}}$ for a Lili at at 42001, b Ivan at 42003, c Rita at 42001, d Katrina at 42003 and e Wilma at 42056 


\subsection{Characterizing overwater Reynolds number during all six hurricanes}

Difference of coefficient in (13-18) remains in each individual hurricane cases, the standard deviation of the two coefficients are 0.39 and 0.40 respectively. However, the strong power-law relationship holds. Combine all the data for the six hurricanes still gives fairly good agreement between the model and data. Relation between $R_{*}$ and $H_{\mathrm{s}}$ is presented in Fig. 9 that:

$R_{*}=0.70 H_{\mathrm{s}}^{2.6}, \quad R^{2}=0.86, \quad R=0.92$.

Now, if we substitute $R_{*}=2.5$ from Eq. (2) into Eq. (19), $H_{\mathrm{s}}=1.6 \mathrm{~m}$. In other words, when $H_{\mathrm{s}}$ are approximately higher than $2 \mathrm{~m}$ or during fresh breeze in Beaufort scale 5 for moderate waves, the airflow over the wind sea is already aerodynamically fully rough. Note that the three 'outlier' dots with $R_{*}>500$ in Fig. 9 are all associated with time when hurricane passed directly through the buoys, future study is needed to investigate whether the wind-wave dynamics within the hurricane eyewall lead to the different behavior of these dots. Sapsis and Haller (2009) shows the extreme vorticity structure along the hurricane eyewall, which could explain the very strong Reynolds number $R_{*}$ in Fig. 9.

\section{Conclusions}

On the basis of aforementioned analyses and discussions, it is concluded that, during six hurricanes as listed in Table 1, when both neutral-stability wind speed at $10 \mathrm{~m}, U_{10}$, and wave steepness, $H_{\mathrm{s}} / L_{\mathrm{p}}$, exceed $9 \mathrm{~m} \mathrm{~s}^{-1}$ and 0.020 , respectively, the roughness Reynolds number can be characterized by a power law using significant wave height, which has a high correlation coefficient of 0.92 . It is found that although most values of $R_{*}$ were below 500, they could reach

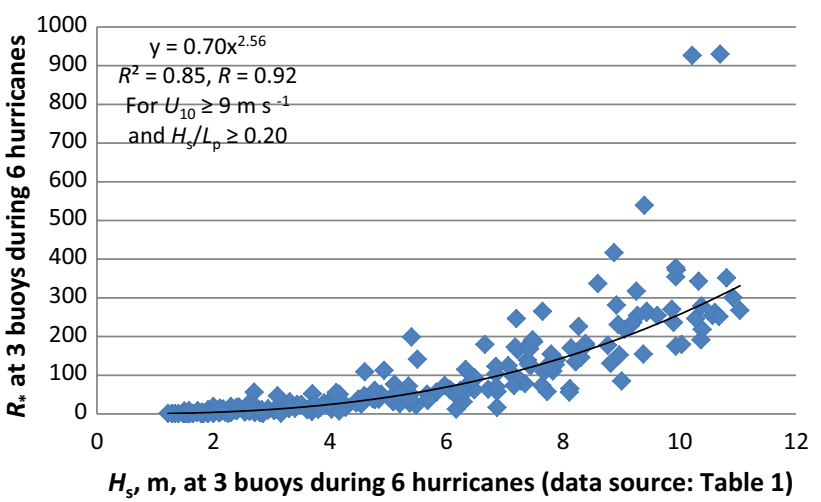

Fig. 9 Relation between $R_{*}$ and $H_{\mathrm{s}}$ at three buoys during six hurricanes to approximately 1000 near the radius of maximum wind. Furthermore, it is found that, when the significant wave height exceeds approximately $2 \mathrm{~m}$ in a wind sea, the air flow over this wind sea is under fully rough conditions, implying that the viscous effect on the wind sea is negligible and that the familiar logarithmic wind profile law is valid over the wind sea. In other words, when the significant wave heights are approximately higher than $2 \mathrm{~m}$ or during fresh breeze in Beaufort scale 5 for moderate waves, the airflow over the wind sea is already aerodynamically fully rough. Additional analyses of simultaneous measurements of wind and wave parameters using the logarithmic wind-profile law indicates that the estimated overwater friction velocity is consistent with other methods including the direct (eddy-covariance flux) measurements, the atmospheric vorticity approach, and the sea-surface current measurements during four slow moving super typhoons with wind speed up to $70 \mathrm{~m} \mathrm{~s}^{-1}$.

Acknowledgements This research was supported in part by the Chinese National Program on Global Change and Air-Sea Interaction (no. GASI-IPOVAI-04) and the international cooperation project of National Natural Science Foundation of China (no. 41620104003).

Open Access This article is distributed under the terms of the Creative Commons Attribution 4.0 International License (http://creativecommons.org/licenses/by/4.0/), which permits unrestricted use, distribution, and reproduction in any medium, provided you give appropriate credit to the original author(s) and the source, provide a link to the Creative Commons license, and indicate if changes were made.

\section{References}

Andreas EL, Mahrt L, Vickers D (2012) A new drag relation for aerodynamically rough flow over the ocean. J Atmos Sci 69:2520-2537

Anthes RA (1982) Tropical cyclones: their evolution, structure and effects. Meteorol Monogr 19(41):208

Bryant KM, Akbar M (2016) An exploration of wind stress calculation techniques in hurricane storm surge modeling. J Mar Sci Eng 4:58

Chang Y-C, Chu PC, Centurioni LR, Tseng R-S (2014) Observed near-surface currents under four super typhoons. J Mar Syst 139:311-319

Csanady GT (2001) Air-sea interaction: laws and mechanisms. Cambridge University Press, New York

Davis C et al (2008) Prediction of landfalling hurricanes with the advanced hurricane WRF model. Mon Weather Rev 136:1990-2005

Drennan WM, Taylor PK, Yelland MJ (2005) Parameterizing the sea surface roughness. J Phys Oceanogr 35:835-848

Edson JB et al (2013) On the exchange of momentum over the open ocean. J Phys Oceanogr 42:1589-1610

Hasse L, Weber H (1985) On the conversion of Pasquill categories for use over sea. Bound Layer Meteorol 31:177-185

Hsu SA (1974) A dynamic roughness equation and its application to wind stress determination at the air-sea interface. J Phys Oceanogr 4:116-120

Hsu SA (2003) Estimating overwater friction velocity and exponent of power-law wind profile from gust factor during storms. ASCE J Waterw Port Coast Ocean Eng 129:174-177 
Kantha L (2008) Tropical cyclone destructive potential by integrated kinetic energy. Bull Am Meteorol Soc 89:219-221

Kraus EB, Businger JA (1994) Atmosphere-ocean interaction, 2nd edn. Oxford University Press, Oxford

Liu B et al (2011) A coupled atmosphere-wave-ocean modeling system: simulation of the intensity of an idealized tropical cyclone. Mon Weather Rev 139:132-152

Rott N (1990) Note on the history of the Reynolds number. Annu Rev Fluid Mech 22:1-11

Sapsis T, Haller G (2009) Inertial particle dynamics in a hurricane. J Atmos Sci 66:2481-2492
Smith RK, Montgomery MT (2010) Hurricane boundary-layer theory. Q J R Meteorol Soc 136:1665-1670

Taylor PK, Yelland MJ (2001) The dependence of sea roughness on the height and steepness of the waves. J Phys Oceanogr 31:572-590

Vickery PJ, Wadhera D, Powell MD, Chen Y (2009) A hurricane boundary layer and wind field model for use in engineering applications. J Appl Meteorol Climatol 48:381-405

Wu J (1975) Wind-induced drift currents. J Fluid Mech 68:49-70

Zeng $\mathrm{Z}$ et al (2010) On sea surface roughness parameterization and its effect on tropical cyclone structure and intensity. Adv Atmos Sci 27:337-355 